\title{
Calcium Permeability of the Nicotinic Acetylcholine Receptor: The Single-Channel Calcium Influx Is Significant
}

\author{
E. Radford Deckera and John A. Dani \\ Department of Molecular Physiology and Biophysics, Baylor College of Medicine, Houston, Texas 77030
}

\begin{abstract}
The calcium permeability of the mouse muscle nicotinic ACh receptor (nAChR) was determined using patch-clamp techniques. Single-channel currents were measured in pure external calcium and in mixtures of calcium with cesium or sodium. At low concentrations, calcium decreases the current carried by the monovalent cation. At higher concentrations, calcium displaces the monovalent cation as the main current carrier. In pure external calcium, the conductance of the nAChR is similar to the conductance of the NMDA receptor or the L-type Ca channel. With pure 110-mM calcium as the external cation, the slope conductance of the nAChR channel at negative potentials is $12 \mathrm{pS}$. An ion-permeation model based on the structure and function of the channel describes the currents. The ion-permeation model predicts that calcium contributes about $2 \%$ of the total inward current through a nAChR channel in physiologic solution. That current is about $7 \%$ of the calcium current through an L-type Ca channel. Because nAChRs are densely packed at the neuromuscular end plate, the calcium influx at an active synapse is expected to produce a locally high-calcium environment.
\end{abstract}

The peripheral nicotinic ACh receptor (nAChR) channel is a pentameric protein structure that provides an aqueous pore through the cell membrane for cations. The primary function of this channel is to depolarize the postsynaptic cell at cholinergic synapses. The $\mathrm{nAChR}$ is permeable to inorganic and organic cations and is impermeable to anions (Takeuchi and Takeuchi, 1960; Huang et al., 1978; Adams et al., 1980, 1981; Dwyer et al., 1980; Sanchez et al., 1986). Current fluctuation analysis and reversal potential measurements showed that divalent cations are permeable and that they decrease the conductance of monovalent cations (Bregestovski et al., 1979; Lewis, 1979; Lewis and Stevens, 1979, 1983; Marchais and Marty, 1979; Adams et al., 1980; Magleby and Weinstock, 1980; Takeda et al., 1982). Single-channel currents showed that magnesium and barium have a relatively high affinity for the channel and that they carry significant current at higher concentrations (Dani and Eisenman, 1987).

\footnotetext{
Received Mar. 29, 1990; revised May 30, 1990; accepted June 8, 1990.

This work was supported by NIH grant NS21229 and by the Muscular Dystrophy Association.

Correspondence should be addressed to John A. Dani, Department of Molecular Physiology and Biophysics, Baylor College of Medicine, One Baylor Plaza, Houston, TX 77030 .

Present address: Department of Physiology and Cell Biology, University of Texas Medical School, Houston, TX 77030.

Copyright (C) 1990 Society for Neuroscience $0270-6474 / 90 / 103413-08 \$ 03.00 / 0$
}

Free calcium ions regulate cells and participate in many biological processes. Therefore, calcium permeation through nAChR channels is of special interest. When Katz and Miledi (1969) replaced normal Ringer's by an isotonic calcium solution, they still saw miniature end-plate potentials, but the potentials were reduced in amplitude. At extremely hyperpolarized potentials, ACh-induced calcium entry at the end plate was detected with arsenazo III (Miledi et al., 1980). Tracer flux measurements, reversal potential measurements, and current fluctuation analysis verified that calcium is permeable and interferes with current carried by monovalent cations (Huang et al., 1978; Bregestovski et al., 1979; Lewis, 1979; Lewis and Stevens, 1979, 1983; Adams et al., 1980; Magleby and Weinstock, 1980).

The purpose of these experiments was to determine the singlechannel calcium permeability, to quantify the influcnce of calcium on the transport of monovalent cations, and to estimate the calcium influx in physiologic solutions. A quantitative understanding of the single-channel permeability of the nAChR is important for evaluating the potential roles of postsynaptic calcium influx at cholinergic synapses.

Current-voltage relations were collected in external solutions of pure calcium and in external mixtures of calcium with sodium or cesium. The current-voltage relations were analyzed using a simple ion-permeation model that is based on the structural and chemical properties of the nAChR channel (Dani, 1986). The physical model accounts for cation binding in the short, narrow region of the pore (Dani, 1989a) and for the channel's wide entrance vestibules (Brisson and Unwin, 1985; Toyoshima and Unwin, 1988), which contain a net negative charge (Huang et al., 1978; Fairclough et al., 1986; Dani and Eisenman, 1987; Imoto et al., 1988; reviewed by Barnard et al., 1987; Dani, 1989b). This physically based model relies on known properties of the channel to produce reasonable fits to the data, rather than introducing more arbitrary, adjustable parameters that would produce more exact fits.

The results show that the channel has a higher affinity for calcium than for monovalent cations. The main effect of millimolar concentrations of calcium is to decrease the current carried by the monovalent cations, but a biologically significant component of the current is carried by calcium. As the concentration of calcium increases, the divalent cation displaces the monovalent cation as the main current carrier. In pure external calcium, the nAChR, the NMDA receptor, and the voltageactivated $\mathrm{Ca}$ channel have a similar inward-going conductance.

Preliminary results of this work were presented at previously held meetings (Decker and Dani, 1988, 1989). 


\section{Materials and Methods}

Nicotinic AChR channels from clonal BC3H-1 mouse muscle cells were studied using patch-clamp techniques. Gigaohm seals were used to measure whole-cell and single-channel currents over a wide range of electrolyte concentrations and membrane potentials.

Tissue culture. Clonal BC3H-1 cells were maintained using standard tissue culture techniques (Sine and Taylor, 1979; Sine and Steinbach, 1984). The cell line was maintained in Dulbecco's Modified Eagle medium (DMEM; Hazleton, Lenexa, KS; Gibco, Gaithersburg, MD) containing 10-20\% heat-inactivated fetal bovine serum (FBS; Gibco, Gaithersburg, MD; Hyclone, Logan, UT), $100 \mathrm{U} / \mathrm{ml}$ penicillin, $100 \mu \mathrm{g} / \mathrm{ml}$ streptomycin (Hazelton, Lenexa, KS), and $2 \mathrm{~mm}$ glutamine (Hazleton, Lenexa, $\mathrm{KS}$ ) in an incubator at $38^{\circ} \mathrm{C}$ with $5 \% \mathrm{CO}_{2}$. The cells were passed to a new flask before becoming $70 \%$ confluent to prevent differentiation. For patch-clamp experiments, the cells were plated onto an ethanolcleaned $9 \times 9-\mathrm{mm}$ coverglass (Bellco Glass Co., Vineland, NJ). Then, the cells were maintained in DMEM with $0.5 \%$ FBS to inhibit cell division, promote differentiation, and increase production of nAChRs. The cells were fed every other day, and they were used from 5 to $20 \mathrm{~d}$ after being plated onto the coverslips.

To enhance patch formation, some experiments were conducted on cells that were treated with enzymes (Dani, 1989a). Four to five d after plating, the cells were bathed for 15-30 min in DMEM, 5 mM HEPES $(\mathrm{pH}, 7.4)$, and $0.1 \%$ collagenase (Type $1 \mathrm{~A}$, Sigma, St. Louis, MO). Then the cells were bathed for $1-5 \mathrm{~min}$ in $150 \mathrm{~mm} \mathrm{NaCl}, 5 \mathrm{~mm} \mathrm{KCl}, 5 \mathrm{~mm}$ HEPES, 5 mm glucose, and $0.0025 \%$ trypsin (Type II, Sigma, St. Louis, MO). The cells were observed under low magnification. The trypsin treatment was stopped by several washes in DMEM with $0.5 \%$ FBS after most of the cells had formed spheres and about $10 \%$ of them had floated away. Cells were then maintained as usual and were used for patch-clamp experiments from 5 to $20 \mathrm{~d}$ after the enzyme treatment.

Patch-clamp techniques. Whole-cell and single-channel nAChR currents were measured using standard patch-clamp techniques (Hamill et al., 1981; Sakmann and Neher, 1983). Patch pipettes were pulled with a 2-stage electrode puller (PP-83, Narishige USA, Greenvale, NY) using 100- $\mu$ l disposable pipettes (Drummond Scientific, Broomall, PA) or Kovar 7052 glass (Garner Glass, Claremont, CA). To decrease capacitive noise, the pipettes were coated with Sylgard silicon elastomer (Dow Corning Corp., Midland, MI). The Sylgard was heated to harden the elastomer, then the pipettes were dipped into polystyrene Q-Dope (GC Electronic, Rockford, IL). The tips were polished immediately before the experiment using a microforge (MF-83, Narishige USA, Greenvale, NY). The platinum wire of the microforge was coated with Kovar glass (Dani and Eisenman, 1987).

Currents were amplified and filtered using a List EPC-7 (Medical Systems, Greenvale, NY) and an 8-pole Bessel filter (LPF 902, Frequency Devices, Haverhill, MA) or an Axopatch $1 \mathrm{~B}$ and the 4-pole Bessel filter of the Axopatch (Axon Instruments, Burlingame, CA). Currents were digitally sampled with a 12-bit analog to digital converter controlled by a PDP 11/73 computer (Indec Systems, Sunnyvale, CA) and saved on the hard disk. The computer system also delivered the holding potentials and voltage ramps through a 12-bit digital to analog output. Currents were sampled every $0.2 \mathrm{msec}$ and filtered at $0.5,1$, or $2 \mathrm{kHz}$. For display in the figures, all the records are filtered at about $0.5 \mathrm{kHz}$.

Current-voltage relationships were determined using outside-out patches. After a patch was excised, it was placed deeply into a U-tube flow system (Dani, 1989a) containing a test solution with 0.5-1 $\mu \mathrm{M} \mathrm{ACh}$ to induce single $n A C h R$-channel openings. The U-tube was formed out of PE 160 tubing. An elongated hole $(1 \times 0.7 \mathrm{~mm})$ was cut into the base of the U. A pressure head of the test solution was applied to one end of the tubing, and a vacuum was applied to the other end. The vacuum and pressure head were balanced to prevent flow out of the hole. The U-tube flow system offered several advantages. By rapidly plunging the patch into the U-tube in the direction of the pressure head, a complete solution change could be made in less than $100 \mathrm{msec}$. Because of the rapid solution change, nAChR openings were seen before the receptors desensitized. Test solution and $\mathrm{ACh}$ did not enter the bath solution. Therefore, the cells were not harmed by the test solution, and the membrane patch could be withdrawn from the $U$ tube to recover from desensitization or from the test solution. The slow flow of solution in the $U$ tube did not introduce noise or disturb the patch.

Only the dominant unitary-current step size was analyzed. In most patches, other current sizes were very rare or absent. Current events had to last for at least 3 sample intervals and be unquestionable channel events before they were included in the averaging used to create currentvoltage relations. The experiments were conducted at room temperature $\left(23^{\circ} \mathrm{C}\right)$.

As described by Dani and Eisenman (1987), single-channel currents obtained while ramping the membrane potential were corrected with analog capacitance and leakage subtraction. The currents were further corrected by subtracting averaged blank base lines from the records that contained single-channel events. Corrected single-channel currents were combined and averaged at each voltage for each patch by computer Each current-voltage relation was standardized to have a current represented every $2 \mathrm{mV}$. Current-voltage relationships created with constant holding potentials overlie current-voltage relationships generated with ramped potentials. If necessary, the zero-current potential was adjusted so that current-voltage relations from different patches in the same solutions could be combined without introducing scatter.

Three different methods were used to accurately determine the reversal potentials. Single-channel currents were determined at positive and negative holding potentials in test solution bracketed by similar single-channel currents in the reference solution. The reversal potentials were determined for both solutions by interpolating between the data to find the zero-current position on the voltage axis. If single-channel currents were too small, whole-cell currents were measured by either lifting a voltage-clamped whole cell from the coverglass and plunging it into the U-tube system (Dani, 1989a) or by picospritzing $5 \mu \mathrm{M} \mathrm{ACh}$ (multi-channel picospritzer, General Valve, Fairfield, NJ) onto a voltage-clamped cell. Then, whole-cell currents were measured at various voltages to determine the reversal potential. Again, determinations in the test solution were bracketed by determinations in a reference solution where the reversal potential was known to be at zero potential.

Solutions. A wide range of electrolyte solutions were used to study whole cells and outside-out membrane patches. In one set of experiments, $45 \mathrm{~mm}$ cesium was the permeant monovalent cation. The internal solution in the pipette usually had the following concentrations: 22.5 $\mathrm{mM} \mathrm{CsCl}, 22.5 \mathrm{~mm} \mathrm{CsOH}, 10 \mathrm{~mm}$ EGTA and $5 \mathrm{~mm}$ HEPES. In some cases, $20 \mathrm{~mm} \mathrm{CsF}$ replaced an equivalent amount of $\mathrm{CsCl}$ plus $\mathrm{CsOH}$. When $\mathrm{CsF}$ was present, $0.5 \mathrm{mM} \mathrm{MgCl}_{2}$ and $0.5 \mathrm{mM} \mathrm{CaCl}_{2}$ were added to the solution. The external solution in the U-tube system was $45 \mathrm{~mm}$ $\mathrm{CsCl}$ and $5 \mathrm{~mm}$ HEPES. In the mixtures of $45 \mathrm{~mm} \mathrm{Cs}$ and $\mathrm{Ca}, 1,10$, 25 , or $40 \mathrm{mM} \mathrm{CaCl}_{2}$ was added to the external solution of $45 \mathrm{~mm} \mathrm{CsCl}$ and $5 \mathrm{mM}$ HEPES. In pure external $\mathrm{CaCl}_{2}$ solutions, 40,56 , or $110 \mathrm{~mm}$ $\mathrm{CaCl}_{2}$ and 5 mM HEPES were present.

In the other set of experiments, 150 mm Na was the permeant monovalent cation. The internal solution in the pipette usually had the following concentrations: $125 \mathrm{~mm} \mathrm{NaCl}, 25 \mathrm{~mm} \mathrm{NaOH}, 10 \mathrm{~mm}$ EGTA, $1.7 \mathrm{mM} \mathrm{MgCl}_{2}, 0.8 \mathrm{mM} \mathrm{CaCl}_{2}$, and $5 \mathrm{mM}$ HEPES. In some cases, the divalent cations were left out of the internal solution. In the mixtures of $150 \mathrm{~mm} \mathrm{Na}$ and $\mathrm{Ca}, 1,10$, or $25 \mathrm{~mm} \mathrm{CaCl}_{2}$ was added to the external solution. The pH of all the solutions was adjusted to 7.4 with $\mathrm{HCl}$ and the hydroxide of the monovalent cation. The osmolarity of the solutions was measured with a vapor pressure osmometer $(5500$, Wescor, Logan, UT). The osmolarity for all the solutions was adjusted to about 0.31 osmolar with sucrose.

The ionic activities in pure solutions were read from tables of mean activity coefficients (Hamer and Wu, 1972; Goldberg and Nuttall, 1978). Measurements to determine the mean activities of the ions in mixtures were made with electrodes specific for monovalent cations (932000, Orion Research, Boston, MA) and divalent cations (476220, Corning, Medfield, MA). A calomel-saturated $\mathrm{KCl}$ fiber-junction electrode (476002, Corning, Medfield, MA) was used as the reference. The voltage was measured with a digital $\mathrm{pH}$ meter (245, Corning, Corning, NY). Pure solutions of $\mathrm{CsCl}, \mathrm{NaCl}$, and $\mathrm{CaCl}_{2}$ served as standards. The final activities of the mixtures were estimated by comparing the ion-specific potentials of the mixtures with the potentials of the pure solutions whose activities were obtained from tables as described by Dani and Eisenman (1987). Rather than using the mean activity coefficient $(\gamma \pm)$ to estimate calcium's activity, we follow the convention of Butler (1968), who suggests that a divalent cation's activity coefficient is given by $\gamma_{++}=(\gamma \pm)^{2}$.

When necessary, liquid-junction potentials were determined as previously described (Dani and Eisenman, 1987; Dani, 1989a). The liquidjunction potentials ranged up to $8.7 \mathrm{mV}$ in the solutions of the monovalent cations and calcium mixtures and up to $10.8 \mathrm{mV}$ in the solutions of pure external calcium.

The charged-channel ion-permeation model. The model has been presented in detail (Dani, 1986) and has been used to describe a large set 

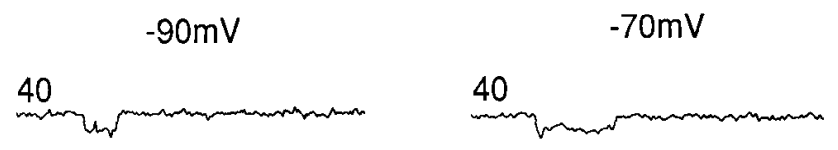

56

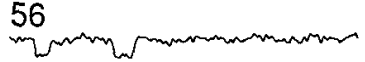

56

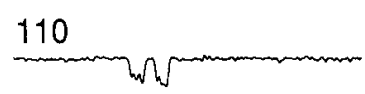

110

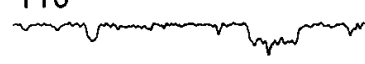

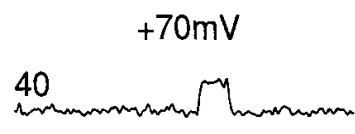

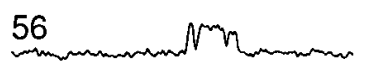

110

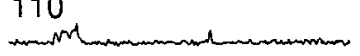

Figure 1. Single-channel currents in pure external calcium. Pure calcium was the external permeant cation and pure $45 \mathrm{~mm}$ Ce was the internal cation. The concentration of external calcium is given to the left of each record. The holding potential is given at the top of each column of records. The inward currents at -90 and $-70 \mathrm{mV}$ were carried by calcium. The single-channel currents were activated by $\mathrm{ACh}$, and no channel activity was seen when the patches of membrane were removed from the ACh. Calibration bars: vertical, 2 pA; horizontal, $10 \mathrm{msec}$. of permeation data (Dani and Eisenman, 1987; Dani, 1988). The total model of permeation combines an equilibrium description of the entrance vestibules with a kinetic description of the channel's narrow region. The model considers the size, shape, and net charge of the channel to describe the data.

The wide entrance vestibules of the channel are modeled to have a net negative charge that attracts a diffuse layer of cations into the channel. A geometry-dependent Poisson-Boltzmann equation describes the diffuse double layer of cations that screens the negatively charged amino acid residues. The total potential experienced by a permeant cation is the sum of the negative potential arising from the negative charge in the vestibule and the positive potential arising from the diffuse ionic layer. The broad energy minima in the vestibules do not behave like simple binding sites that saturate; rather, they can contain many ions. Therefore, the vestibules serve as transition zones from the bulk solution, and they condition the environment next to the narrow region of the channel, where the permeant cation more strongly interacts with the walls.

Eyring rate theory is used to describe the interactions between the permeant cation and the channel walls in the narrow region of the pore. Although there are many binding sites for cations within the pore, there is one main binding site that is directly in the permeation pathway (Dani, 1989a). The interactions in the narrow region are approximated by a 2 -barrier, 1 -site rate-theory model. In Figure 6 , the charged-channel model is used to predict the individual currents in a physiologic solution of $150 \mathrm{~mm} \mathrm{NaCl}$ and $1 \mathrm{mM} \mathrm{MgCl}$ inside and outside plus $2.5 \mathrm{mM} \mathrm{CaCl}_{2}$ outside. In the presence of 3 permeant species, absolute rate theory gives the steady-state probabilities for occupancy of the site in the 2-barrier, 1 -site energy profile. The probabilities are given by the following equations:

$$
\begin{aligned}
p_{e}= & \left(k_{i 1} k_{i 2} k_{i 3}+k_{-o 1} k_{-o 2} k_{-o 3}+k_{i 1} k_{i 2} k_{-o 3}+k_{i 1} k_{-o 2} k_{i 3}+k_{i 1} k_{-o 2} k_{-o 3}\right. \\
& \left.+k_{-o 1} k_{i 2} k_{-o 3}+k_{-o o} k_{-o 2} k_{i 3}+k_{-o 1} k_{i 2} k_{i 3}\right) \\
p_{1}= & \left(C_{i 1} k_{-i 1}+C_{o 1} k_{o 1}\right)\left(k_{i 2} k_{i 3}+k_{i 2} k_{-o 3}+k_{-o 2} k_{i 3}+k_{-o 2} k_{-o 3}\right) \\
p_{2}= & \left(C_{i 2} k_{-i 2}+C_{o 2} k_{o 2}\right)\left(k_{i 1} k_{i 3}+k_{i 1} k_{-o 3}+k_{-o 1} k_{i 3}+k_{-o 1} k_{-o 3}\right) \\
p_{3}= & \left(C_{i 3} k_{-i 3}+C_{o s} k_{o 3}\right)\left(k_{i 1} k_{i 2}+k_{i 1} k_{-o 2}+k_{-o 1} k_{i 2}+k_{-o 1} k_{-o 2}\right) \\
D= & p_{e}+p_{1}+p_{2}+p_{3}
\end{aligned}
$$

where the probability of the site being empty is $P_{e}=p_{e} / D$, the probability of the site bcing occupicd by specics 1 is $P_{1}=p_{1} / D$, the probability of the site being occupied by species 2 is $P_{2}=p_{2} / D$, and the probability of the site being occupied by species 3 is $P_{3}=p_{3} / D$. The symbols represent a rate constant $(k)$, the outer barrier $(o)$, the inner barrier $(i)$, the cation species $(1,2$, or 3$)$, and the activity $(C)$. The steady-state current is the same over either barrier and is equal to the difference in the 1-way fluxes. The steady-state current calculated over the outer barrier, with inward current defined as negative, is $I=e\left(z_{1} P_{1} k_{-o_{1}}+\right.$ $\left.z_{2} P_{2} k_{-n 2}+z_{3} P_{3} k_{-o 3}-z_{1} C_{o 1} P k_{o 1}-z_{2} C_{n 2} P k_{o 2}-z_{3} C_{n 3} P_{e} k_{n 3}\right)$, where $e$ is the elemental change and $z$ is the valence of the permeant cation.

\section{Results}

\section{Single-channel calcium currents}

Figure 1 shows single-channel currents with pure calcium as the external permeant cation and pure $45 \mathrm{~mm}$ Cs as the internal permeant cation. Under those electrolyte conditions, inward current is carried by calcium and outward current is carried by cesium. The calcium conductance was estimated from the single-channel slope conductance at potentials more negative than $-100 \mathrm{mV}$. In $40 \mathrm{mM} \mathrm{Ca}$, the conductance is $9 \mathrm{pS}$, and in 110 $\mathrm{mm} \mathrm{Ca}$, the conductance is $12 \mathrm{pS}$. Therefore, calcium carries significant current through the $\mathrm{nAChR}$ channel.

\section{Calcium influences the conductance of monovalent cations}

Figure 2 shows single-channel currents and current-voltage relations in pure cesium and in external mixtures of cesium and calcium. With pure $45 \mathrm{~mm}$ Cs bathing both sides of the membrane, the channel has a slope conductance of about $62 \mathrm{pS}$ at negative potentials. When only $1 \mathrm{~mm}$ or $10 \mathrm{~mm} \mathrm{Ca}$ is added to the external cesium solution, the inward currents are dramatically reduced. Adding $1 \mathrm{~mm}$ or $10 \mathrm{~mm} \mathrm{Ca}$ reduces the slope conductance at negative potentials to $28 \mathrm{pS}$ and $16 \mathrm{pS}$, respectively. The effect of the calcium on the cesium currents indicates that calcium has a relatively high affinity for the $\mathrm{nAChR}$ channel.

Low concentrations of calcium also influence the currents in more physiologic solutions. Figure 3 shows single-channel currents and current-voltage relations in $150 \mathrm{mM} \mathrm{Na}$ with and without added calcium. Adding $1 \mathrm{~mm} \mathrm{Ca}$ to the external sodium slightly decreases the inward currents, but the effect of $10 \mathrm{~mm}$ and $25 \mathrm{~mm} \mathrm{Ca}$ is more significant. At negative potentials, the single-channel slope conductance is $51 \mathrm{pS}$ in $150 \mathrm{~mm} \mathrm{Na}$. The slope conductance at negative potentials falls to $24 \mathrm{pS}$ and 21 pS when $10 \mathrm{~mm}$ or $25 \mathrm{~mm} \mathrm{Ca}$, respectively, is added to the external sodium. Even at a physiologic concentration of sodium, calcium influences the conductance because the channel has a higher affinity for calcium.

Figure 4 is a plot of the slope conductance at negative potentials as a function of the activity of calcium in the external solution. The internal permeant cation is always pure $45 \mathrm{~mm}$ Cs. The solid circles in Figure 4 are conductances with $45 \mathrm{~mm}$ $\mathrm{Cs}$ in the external solution. The solid triangles are conductances with pure calcium in the external solution. Figure 4 shows 2 qualitative effects of calcium. At low concentrations, calcium reduces the current carried by the monovalent cation. At higher calcium concentrations, calcium seems to become the main current carrier because the conductances are about the same whether or not $45 \mathrm{~mm}$ Cs is added to the external solution.

\section{A physical-permeation model that describes the results}

The nAChR channel has wide entrance vestibules (Toyoshima and Unwin, 1988) that narrow to a minimum diameter of about $0.9 \mathrm{~nm}$ (Dwyer et al., 1980). The minimum cross section of the pore is short and probably provides the main ion-binding site that is directly in the permeation pathway (Dani, 1989a). A 

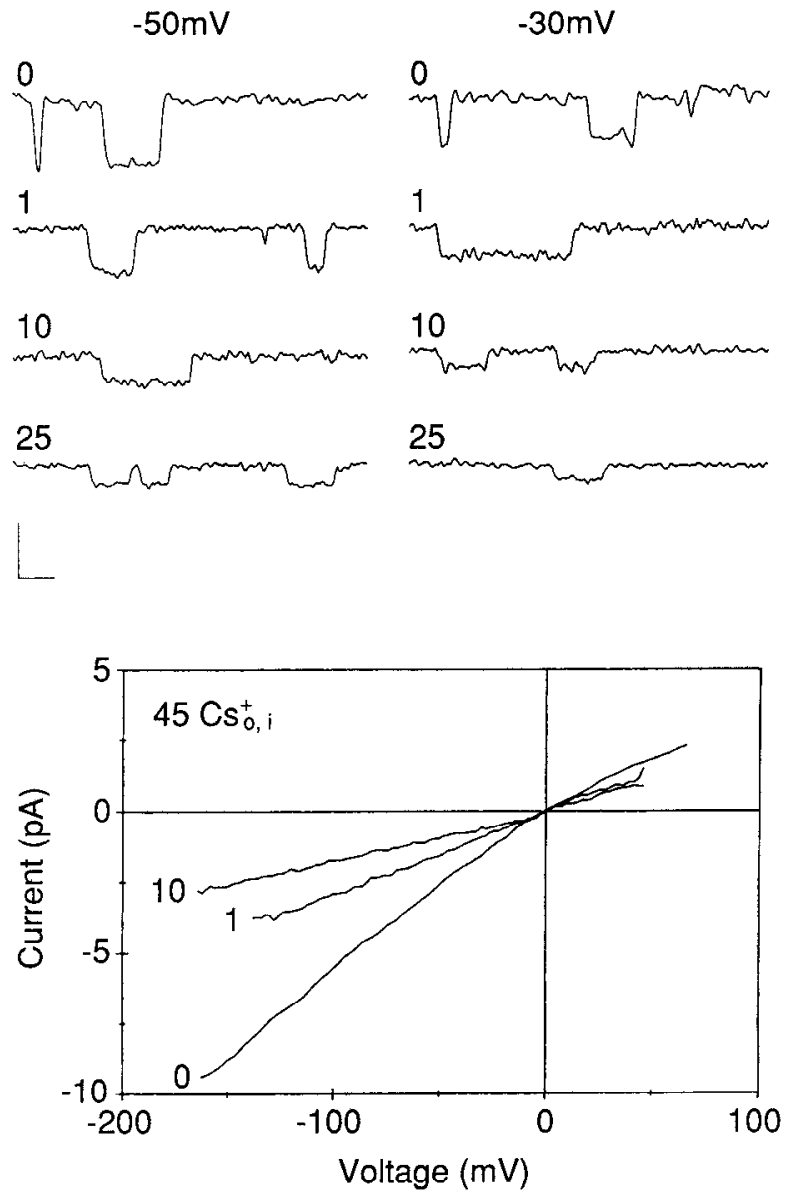

Figure 2. Single-channel currents and current-voltage relations. The internal solution was always pure $45 \mathrm{~mm} \mathrm{Cs}$, and the external solution contained $45 \mathrm{~mm}$ Cs plus the concentration of calcium given to the left of each single-channel record or current-voltage curve. The inwardgoing currents are reduced by adding only $1 \mathrm{~mm} \mathrm{Ca}$. The current reduction by calcium is voltage dependent; therefore, there is still a small current reduction at low positive potentials (see Dani and Eisenman, 1987). At several potentials, our single-channel records in pure symmetrical cesium agreed with the current-voltage relation obtained by Dani and Eisenman (1987), which is shown here. Calibration bars: vertical, $2 \mathrm{pA}$; horizontal, 10 msec.

variety of results indicate that M2 is the transmembrane $\alpha$-helix that lines the pore (Giraudat et al., 1986; Hucho et al., 1986; Imoto et al., 1986, 1988; Leonard et al., 1988; reviewed by Dani, 1989b). Helix M2 is uncharged and is flanked by net negative charge. Those net negatively charged amino acids produce a negative potential that attracts a diffuse double layer of cations into the vestibules. Therefore, the vestibules serve as transition zones from the bulk solution to the narrower region of the channel, where more direct ion-channel interactions dictate permeation. The ion-permeation data can be described by a permeation model that accounts for these physical properties of the channel (Dani, 1986).

In the permeation model, the main features of the channel are considered in a simplified way so that data can be fit with few adjustable parameters. The potential and diffuse double layer of cations in the vestibules are modeled by a PoissonBoltzmann equation that explicitly includes the net charge, size, and shape of the vestibules. The specific interactions at the narrow region are represented by a binding site between 2 energy barriers using absolute reaction-rate theory. The charged-chan-
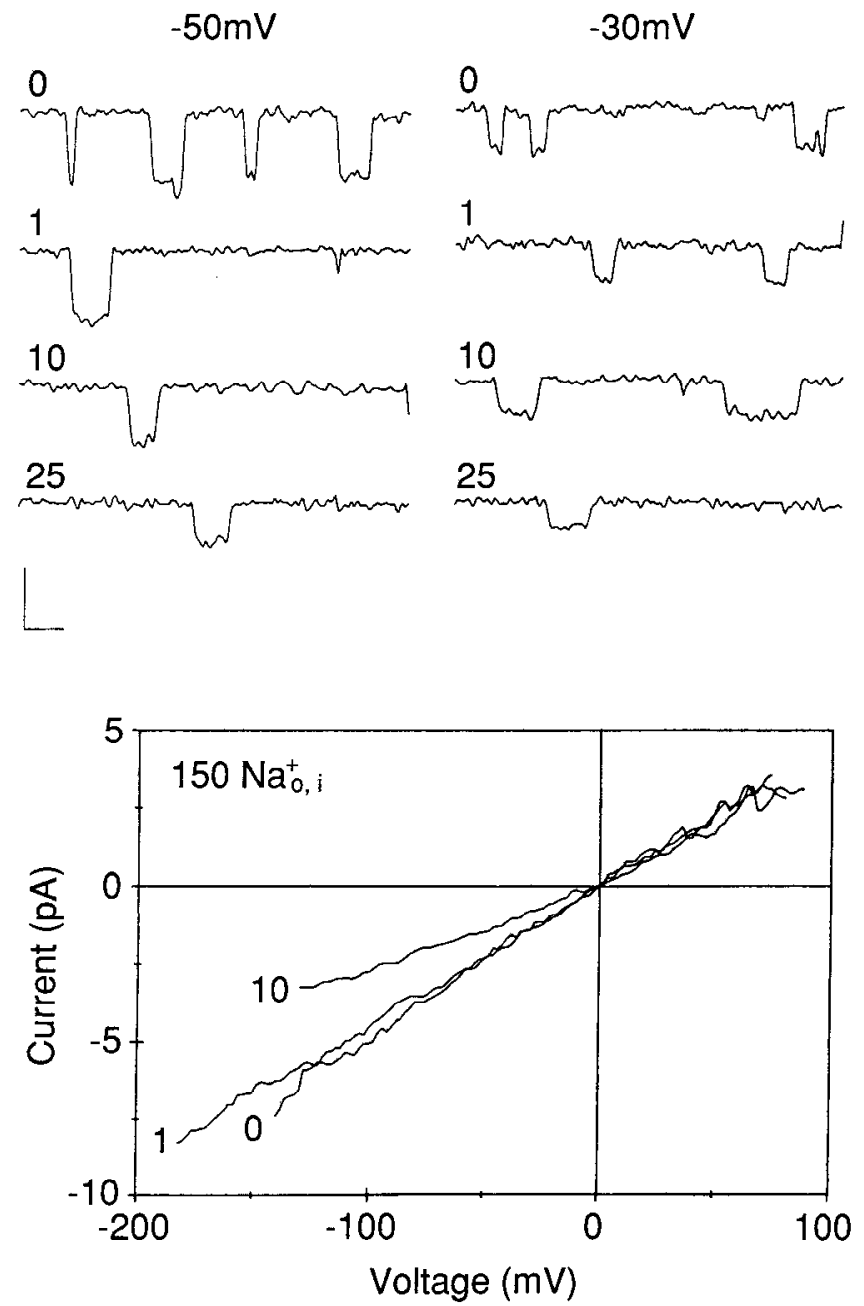

Figure 3. Single-channel currents and current-voltage relations. The internal solution was always pure $150 \mathrm{mM} \mathrm{Na}$, and the external solution contained $150 \mathrm{~mm}$ Na plus the concentration of calcium given to the left of each single-channel record or current-voltage curve. Added external calcium reduces the amplitude of the inward going single-channel currents. Calibration bars: vertical, $2 \mathrm{pA}$; horizontal, $10 \mathrm{msec}$.

nel ion-permeation model has been presented in detail elsewhere (Dani, 1986).

The ion-permeation model uses no adjustable parameters to describe the ionic behavior in the vestibules. Instead, reasonable values are taken for the size, shape, and net charge of the vestibules (Brisson and Unwin, 1985). Both vestibules are given a single negative charge. The outer vestibule is modeled as 2.6 $\mathrm{nm}$ wide and $6.5 \mathrm{~nm}$ long, and the inner vestibule as $1.6 \mathrm{~nm}$ wide and $3.0 \mathrm{~nm}$ long. Adjustable parameters are included in the rate-theory description of the narrow region. The energies of the 2 barriers and 1 binding site that describe the narrow region are adjusted so the overall permeation model can fit the current-voltage data. Each ionic species that passes through the pore is expected to have its own interaction energies with the amino acid residues. The energies for sodium, cesium, and magnesium were obtained previously by fitting the model to other permeation data sets (Dani and Eisenman, 1987). Because the locations of the barriers and site are expected to be a property of the channel, the locations were not used as adjustable parameters. Instead, the locations of the barriers and site were fixed 


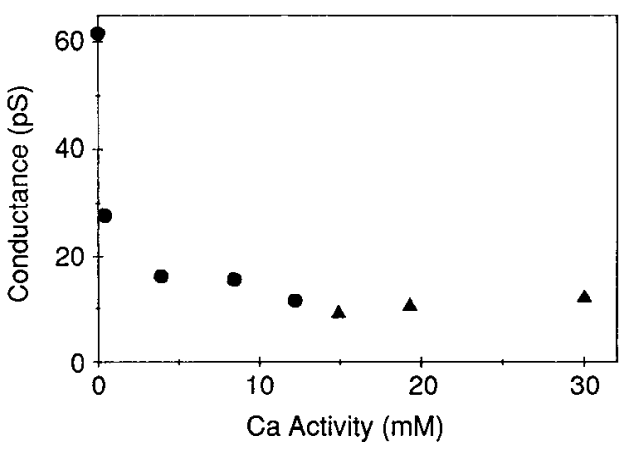

Figure 4. Calcium becomes the major current carrier at high concentrations. The slope conductance at negative potentials is plotted against the external calcium activity. In all cases, pure $45 \mathrm{~mm}$ Cs is the internal permeant cation. The solid circles represent conductances with $45 \mathrm{mM}$ $\mathrm{Cs}$ in the external solution. Except for the $y$-intercept $(\mathrm{Ca}=0$, conductance $=62 \mathrm{pS}$ ), calcium was added to the external solutions of cesium (solid circles). Adding only a small amount of calcium caused a large decrease in the conductance. The solid triangles represent conductances with pure calcium in the external solution. The conductance in pure calcium is similar to the conductance when $45 \mathrm{mM}$ Cs was added, suggesting that calcium is the main current carrier. The slope conductances were estimated by fitting a line to the current-voltage relations at the limiting negative potentials (usually the last $50 \mathrm{mV}$ ).

at one position determined previously. Defined as the fraction of the voltage drop to that position, the locations are as follows: outer barrier at 0.165 , binding site at 0.620 , and inner barrier at 0.804 . The energies of interaction of sodium and cesium did not change significantly from the values determined earlier. Therefore, to fit all 11 current-voltage relations, only the 3 interaction energies for calcium were used as adjustable parametcrs. Those parameters represent the energies encountered by calcium during permeation. The energies at the outer barrier, at the binding site, and at the inner barrier are the following:
(RT units): $7.515,-7.151$, and 9.732 for calcium; $6.398,-4.196$, and 8.428 for sodium; and $6.352,-3.886$, and 8.374 for cesium. Figure 5 shows the data and theoretical fits obtained from the charged-channel permeation model.

\section{Discussion}

There are 3 main qualitative features of calcium transport through the $\mathrm{nAChR}$ channel. Calcium has a relatively high affinity for the channel. Calcium decreases the current carried by monovalent cations. In high concentrations, calcium displaces the monovalent cation as the main current carrier.

\section{Comparison of the calcium permeability of the $n A C h R$, the NMDA receptor, and the Ca channel}

Voltage-gated $\mathrm{Ca}$ channels and the NMDA subtype of the glutamate receptors provide biologically important pathways for calcium influx into cells. The NMDA receptor shares some characteristics with the nAChR. They are both synaptic channels that weakly select among cations, and they have a conductance near $45 \mathrm{pS}$ in physiologic solutions (reviewed by Mayer and Westbrook, 1987a). Calcium influx through the NMDA receptor (Jahr and Stevens, 1987; Mayer and Westbrook, 1987b; Ascher and Nowak, 1988) has been implicated in many important biological processes, including long-term potentiation and cxcitotoxicity (reviewed by MacDermott and Dale, 1987; Rothman and Olney, 1987). The voltage-gated Ca channels are responsible for calcium action potentials (reviewed by Tsien et al., 1988). These channels regulate many cellular functions, including neurotransmitter release and some muscle contractions. In pure solutions, the nAChR conducts calcium as well as the NMDA receptor or the cardiac L-type Ca channel. In pure $110 \mathrm{~mm} \mathrm{Ca}$, the conductances at negative potential are as follows: $12 \mathrm{pS}$ for the nAChR, $14 \mathrm{pS}$ for the NMDA receptor (Ascher and Nowak, 1988), and $9 \mathrm{pS}$ for the Ca channel (Hess et al., 1986).

A more important value, however, is the calcium influx in

$$
\begin{array}{ll}
\mathrm{Ca}_{\mathrm{o}}^{++}, 150 \mathrm{Na}_{0}^{+} & \mathrm{Ca}_{0}^{++}, 45 \mathrm{Cs}_{0}^{+} \\
150 \mathrm{Na}_{\mathrm{i}}^{+} & 45 \mathrm{Cs}_{\mathrm{i}}^{+}
\end{array}
$$
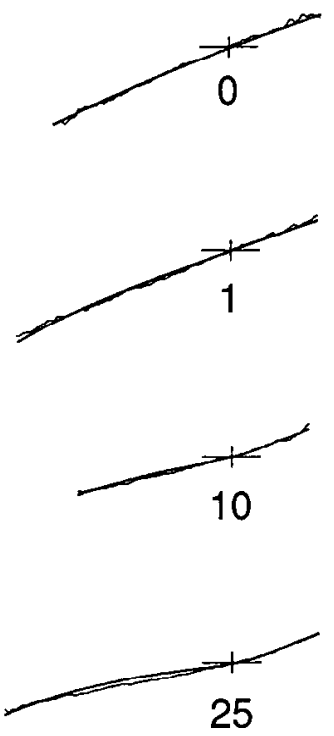
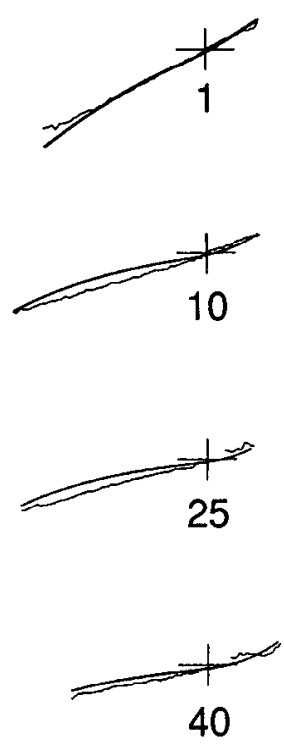
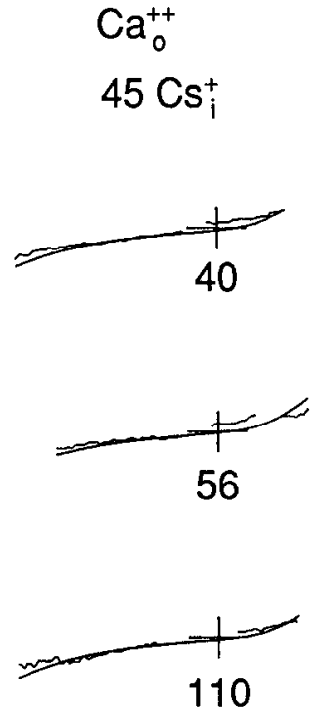

Figure 5. Charged-channel model fitted to the current-voltage relations. The noisy current-voltage relations are the data, and the smooth curves are the theoretical fits of the charged-channel ionpermeation model. The concentration of external calcium is given below each current-voltage relation. The first column had $150 \mathrm{~mm} \mathrm{Na}$ on both sides of the membrane. The second column had $45 \mathrm{~mm}$ Cs on both sides of the membrane. The third column had pure calcium on the outside and $45 \mathrm{~mm}$ Cs on the inside. The 0,0 position is indicated by the crossed calibration bars that run vertically from -1 to $1 \mathrm{pA}$ and horizontally from -25 to $25 \mathrm{mV}$. 
A

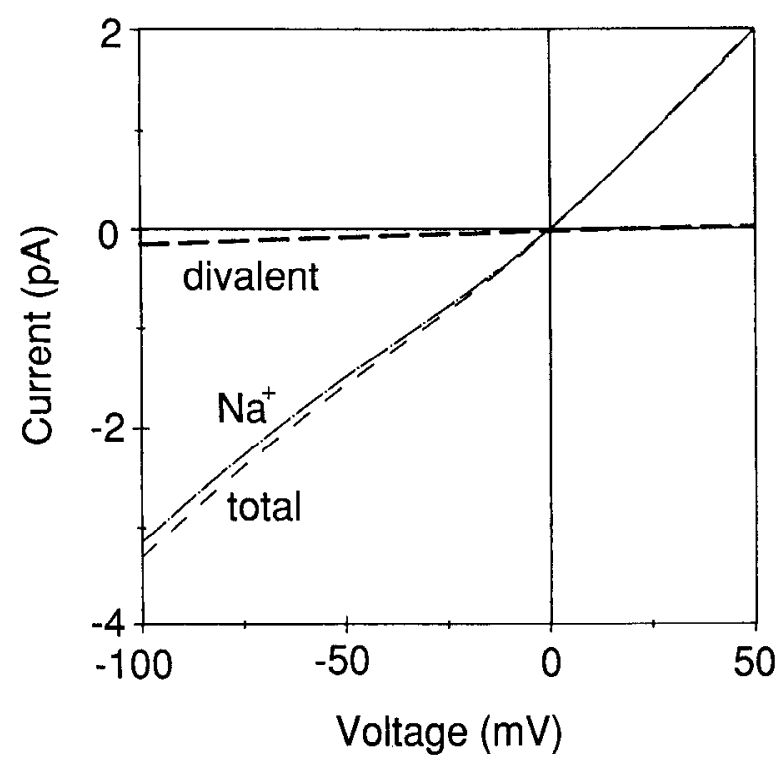

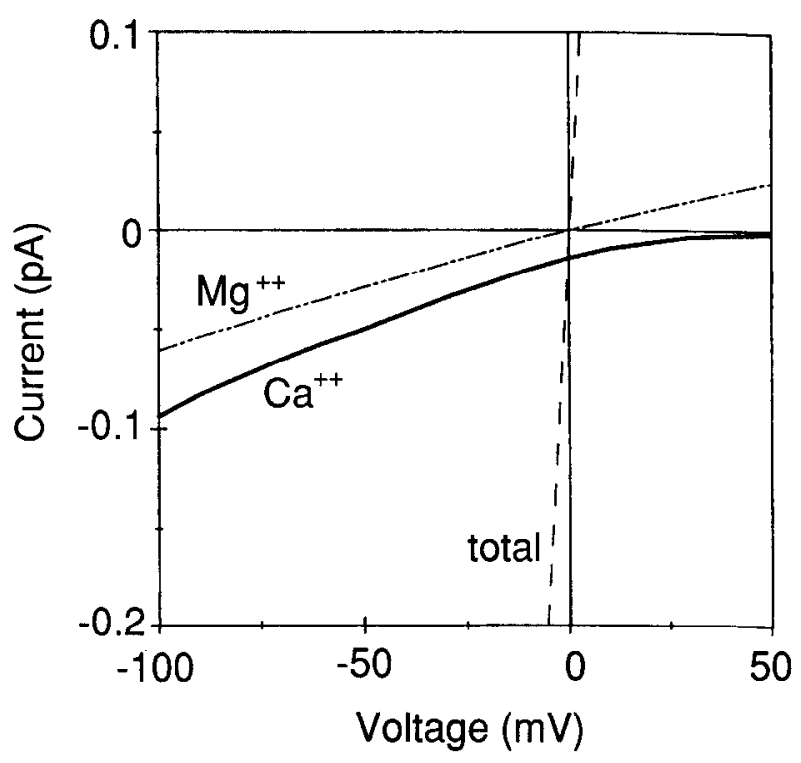

Figure 6. Current-voltage relations predicted by the charged-channel model in a physiologic solution. The physiologic solution was the following (with millimolar activities in parenthesis): $2.5 \mathrm{mM} \mathrm{CaCl}_{2}(0.7)$ outside, $150 \mathrm{~mm} \mathrm{NaCl} \mathrm{(115),} \mathrm{and} 1 \mathrm{~mm} \mathrm{MgCl}_{2}(0.3)$ inside and outside. The species carrying the current is given next to each current-voltage relation. The current-voltage relation labeled as total current (thin dashed curve) is the same relation in both panels. $A$, The divalent current-voltage relation (thick dashed curve) is the sum of the current carried by calcium and magnesium. $B$, The current axis scale has been expanded by a factor of 20 . The current-voltage relations for magnesium and calcium are shown separately. The calcium current-voltage relation (thick solid curve) indicates that significant inward calcium current is carried even near $0 \mathrm{mV}$.

physiologic solutions. For the nAChR channel, we are in a position to predict the calcium influx based on the charged-channel permeation model. Figure 6 shows the predicted current-voltage relations in a solution of $150 \mathrm{mM} \mathrm{NaCl}$ and $1 \mathrm{mM} \mathrm{MgCl}_{2}$ inside and outside plus $2.5 \mathrm{~mm} \mathrm{CaCl} 2$ outside. A significant amount of current is carried by divalent cations (Fig. $6 A$ ). At negative potentials, about $2 \%$ of the inward current is carried by calcium, and that percentage increases near $0 \mathrm{mV}$ (Fig. 6B). Even when there is net outward current, there is still inward calcium movement because of the calcium concentration difference across the membrane. A very active synapse functions at depolarized potentials where the fraction of inward current carried by calcium is greater.

The calcium influx calculated for the $\mathrm{nAChR}$ can be compared with an estimate of the calcium current through a Ca channel in the physiologic solution of $2.5 \mathrm{~mm} \mathrm{Ca}$. Hess et al. (1986) made single-channel measurements of L-type Ca channels from ventricular heart cells. Based on the concentration dependence of the single-channel currents, an estimate for the calcium current is $0.2 \mathrm{pA}$ at $0 \mathrm{mV}$. At the same potential, the current carried by calcium through the $\mathrm{nAChR}$ is $0.014 \mathrm{pA}$ (Fig. $6 B$ ). Under physiologic conditions, the calcium current achieved through an $\mathrm{nAChR}$ channel is about $7 \%$ of the calcium current achieved through the cardiac L-type $\mathrm{Ca}$ channel.

It is also interesting to compare the density of $\mathrm{nAChRs}$ and Ca channels. Binding and microscopic methods have been used to estimate the density of nAChRs at the neuromuscular junction. The most likely value is about 10,000 receptors per $\mu \mathrm{m}^{2}$ at the top of the junctional folds (reviewed by Salpeter, 1987). About $50 \%$ of the channels are opened by rapid application of ACh (reviewed by Adams, 1987). So there are $5000 \mathrm{nAChRs/}$ $\mu \mathrm{m}^{2}$, each carrying $7 \%$ of the calcium carried by a Ca channel. Schwartz et al. (1985) estimated that there are about 6 functional $\mathrm{Ca}$ channels per $\mu \mathrm{m}^{2}$ in frog muscle. Therefore, at the top of the junctional folds of the neuromuscular endplate, the calciumcurrent density through $\mathrm{nAChRs}$ could be about 50 times greater than the average calcium-current density through $\mathrm{Ca}$ channels. This, of course, is a rough estimate because $\mathrm{Ca}$ channels form clusters (Silver et al., 1990), and the neuromuscular junction is not uniformly active (reviewed by Rash et al., 1988). Even with a heterogeneous distribution of nAChRs, however, an activitydependent local environment of calcium may exist beneath an end plate (Zucker, 1985). This expectation has important implications for the regulation and plasticity of cholinergic synapses.

\section{Roles of calcium at cholinergic synapses}

Calcium has varied effects on $\mathrm{nAChRs}$ and cholinergic synapses. Calcium may directly alter desensitization (Parsons et al., 1974; Parsons, 1978; but see Clapham and Neher, 1984) and modulate nAChR clustering (Bloch and Steinbach, 1981; Bloch, 1983; Peng, 1984). In addition, calcium participates in second-messenger systems that regulate phosphorylation and other enzyme activity (see Nestler and Greengard, 1984). For example, calcium in concert with protein kinase activity may be a link between electrical activity and $\mathrm{nAChR}$ synthesis (McManaman et al., 1981; Rubin, 1985; Fontaine et al., 1987; reviewed by Laufer and Changeux, 1989).

Calcium permeation through nAChRs could be an important component of these synaptic processes. Calcium arriving via $\mathrm{nAChRs}$ would be precisely in the area defined by the end plate. The same area where the calcium arrives is also the location of 
the biosynthetic machinery that produces postsynaptic specializations. Nuclei of muscle cells associate near the synaptic end plate (Englander and Rubin, 1987), and synthesis at these nuclei provides a source of molecules usable by that end plate (Merlie and Sanes, 1985). The Golgi apparatus is focally located underneath innervated motor end plates (Jasmin et al., 1989). Therefore, calcium influx through nAChRs could provide an immediate activity-dependent signal that regulates processes vital for postsynaptic integrity and plasticity.

The role of calcium influx through neuronal nAChRs could be even more varied. Neuronal nAChRs have both a presynaptic and postsynaptic location. Their main function is to modulate the excitability and firing rate of neurons (Brown et al., 1983). The calcium influx accompanying $\mathrm{ACh}$-induced currents could participate in the modulation of excitability. For example, calcium influx through presynaptic nAChRs could alter excitationsecretion coupling. Stimulation of postsynaptic nAChRs could affect calcium-dependent channels. Synaptic transmission could then be altered by the resulting change in the input resistance of the postsynaptic membrane. These rapid modes of modulation could be coupled to the longer-term action of calcium on enzyme systems, as hypothesized for the NMDA receptor. Although the main role of the $\mathrm{nAChR}$ channel is to depolarize the postsynaptic cell, the calcium permeability suggests involvement in other processes.

\section{References}

Adams PR (1987) Transmitter action at endplate membrane. In: The vertebrate neuromuscular junction (Salpeter MM, ed), pp 317-360. New York: Alan R. Liss.

Adams DJ, Dwyer TM, Hille B (1980) The permeability of endplate channels to monovalent and divalent metal cations. J Gen Physiol 75:493-510.

Adams DJ, Nonner W, Dwyer TM, Hille B (1981) Block of endplate channels by permeant cations in frog skeletal muscle. J Gen Physiol 78:593-615.

Ascher P, Nowak L (1988) The role of divalent cations in the $N$-methyl-D-aspartate responses of mouse central neurones in culture. J Physiol (Lond) 399:247-266.

Barnard EA, Darlison MG, Seeburg P (1987) Molecular biology of the $\mathrm{GABA}_{\mathrm{a}}$ receptor: the receptor/channel superfamily. Trends Neurosci 10:502-509.

Bloch RJ (1983) Acetylcholine receptor clustering in rat myotubes: requirement for $\mathrm{Ca}^{2+}$ and effects of drugs which depolymerize microtubules. J Neurosci 3:2670-2680.

Bloch RJ, Steinbach JH (1981) Reversible loss of acetylcholine receptor clusters at the developing rat neuromuscular junction. Dev Biol 81:386-391.

Bregestovski PD, Miledi R, Parker I (1979) Calcium conductance of acetylcholine induced end-plate channels. Nature 279:638-639.

Brisson A, Unwin PNT (1985) Quaternary structure of the acetylcholine receptor. Nature 315:474-477.

Brown DA, Docherty RJ, Halliwell JV (1983) Chemical transmission in the rate interpeduncular neucleus in vitro. J Physiol (Lond) 341: $655-670$.

Butler JN (1968) The thermodynamic activity of calcium ion in sodium chloride-calcium chloride electrolytes. Biophys J 8:1426-1433.

Clapham DE, Neher E (1984) Substance P reduces acetylcholine-induced currents in isolated bovine chromaffin cells. J Physiol (Lond) 347:255-277.

Dani JA (1986) Ion-channel entrances influence permeation: net charge, sizc, shape, and binding considerations. Biophys J 49:607-618.

Dani JA (1988) Ionic permeability and the open channel structure of the nicotinic acetylcholine receptor. In: Transport through membranes: carriers, channels and pumps (Pullman A, Jortner J, Pullman B, eds), pp 297-320. Dordrecht, Holland: D. Reidel.

Dani JA (1989a) Open channel structure and ion binding sites of the nicotinic acetylcholine receptor channel. J Neurosci 9:882-890.

Dani JA (1989b) Site-directed mutagenesis and single-channel cur- rents define the ionic channel of the nicotinic acetylcholine receptor. Trends Neurosci 12:125-128.

Dani JA, Eisenman G (1987) Monovalent and divalent cation permeation in acetylcholine receptor channels: ion transport related to structure. J Gen Physiol 89:959-983.

Decker ER, Dani JA (1988) Permeability properties of the AChR channel to calcium. Biophys J 53:357a.

Decker ER, Dani JA (1989) Calcium permeability of the nicotinic acetylcholine receptor channel determined from single-channel measurements in $\mathrm{BC} 3 \mathrm{H} 1$ cells. Biophys J 55:551a.

Dwyer TM, Adams DJ, Hille B (1980) The permeability of the endplate channel to organic cations in frog muscle. J Gen Physiol 75: 469-492.

Englander LL, Rubin LL (1987) Acetylcholine receptor clustering and nuclear movement in muscle fibers in culture. J Cell Biol 104:87-95.

Fairclough RH, Miake-Lye RC, Stroud RM, Hodgson KO, Doniach S (1986) Location of terbium binding sites on acetylcholine receptorenriched membranes. J Mol Biol 189:673-680.

Fontaine B, Klarsfeld A, Changeux JP (1987) Calcitonin-gene related peptide and muscle activity regulate acetylcholine receptor $\alpha$-subunit mRNA levels by distinct intracellular pathways. J Cell Biol 105:13371342.

Giraudat J, Dennis M, Heidmann T, Chang J-Y, Changeux .I-P (1986) Structure of the high-affinity binding site for noncompetitive blockers of the acetylcholine receptor: serine-262 of the delta subunit is labeled by [ $\left.{ }^{3} \mathrm{H}\right]$ chlorpromazine. Proc Natl Acad Sci USA 83:2719-2723.

Goldberg RN, Nuttall RL (1978) Evaluated activity and osmotic coefficients for aqueous solutions: the alkaline earth metal halides. $J$ Phys Chem Ref Data 7:263-310.

Hamer WJ, Wu Y-C (1972) Osmotic coefficients and mean activity coefficients of uni-univalent electrolytes in water at $25^{\circ} \mathrm{C}$. J Phys Chem Ref Data 1:1047-1099.

Hamill OP, Marty A, Neher E, Sakmann B, Sigworth FJ (1981) Improved patch-clamp techniques for high-resolution current recordings from cells and cell-free membrane patches. Pflügers Arch 391:85100.

Hess P, Lansman JB, Tsien RW (1986) Calcium channel selectivity for divalent and monovalent cations. J Gen Physiol 88:293-319.

Huang LM, Catterall WA, Ehrenstein G (1978) Selectivity of cations and nonelectrolytes for acetylcholine-activated channels in cultured muscle cells. J Gen Physiol 71:397-410.

Hucho F, Oberthur W, Lottspeich F (1986) The ion channel of the nicotinic acetylcholine receptor is formed by the homologous helices MII of the receptor subunits. FEBS Lett 205:137-142.

Imoto K, Methfessel C, Sakmann B, Mishina M, Mori Y, Konno T, Fukuda K, Kurasaki M, Bujo H, Fujita Y, Numa S (1986) Location of the $\delta$-subunit region determining ion transport through the acetylcholine receptor channel. Nature 324:670-674.

Imoto K, Busch C, Sakmann B, Mishina M, Konno T, Nakai J, Bujo H, Mori Y, Fukuda K, Numa S (1988) Rings of negatively charged amino acids determine the acetylcholine receptor channel conductance. Nature 335:645-648.

Jahr CE, Stevens CF (1987) Glutamate activates multiple single channel conductances in hippocampal neurons. Nature 325:522-525.

Jasmin BJ, Cartaud J, Bornens M, Changeux J-P (1989) Synaptic plasticity in skeletal muscle: changes in the Golgi apparatus distribution during development and after denervation. Neurosci Abstr 15: 1351.

Katz B, Miledi R (1969) Spontaneous and evoked activity of motor nerve endings in calcium Ringer. J Physiol (Lond) 203:689-706.

Laufer R, Changeux J-P (1989) Activity-dependent regulation of gene expression in muscle and neuronal cells. Mol Neurobiol 3:1-53.

Leonard RJ, Labarca CG, Charnet P, Davidson N, Lester H (1988) Evidence that the $\mathrm{M} 2$ membrane-spanning region lines the ion channel pore of the nicotinic receptor. Science 242:1578-1581.

Lewis CA (1979) Ion-concentration dependence of the reversal potential and the single channel conductance of ion channels at the frog neuromuscular junction. J Physiol (Lond) 286:417-455.

Lewis CA, Stevens CF (1979) Mechanism of ion permeation through channels in a postsynaptic membrane. In: Membrane transport processes, pp 89-103. Vol 3 (Stevens CF, Tsien RW, eds), New York: Raven.

Lewis CA, Stevens CF (1983) Acetylcholine receptor channel ionic selectivity: ions experience an aqueous environment. Proc Natl Acad Sci USA 80:6110-6113. 
MacDermott AB, Dale N (1987) Receptors, ion channels and synaptic potentials underlying the integrative actions of excitatory amino acids. Trends Neurosci 10:280-284.

Magleby KL, Weinstock MM (1980) Nickel and calcium ions modify the characteristics of the acetylcholine receptor-channel complex at the frog neuromuscular junction. J Physiol (Lond) 299:203-218.

Marchais D, Marty A (1979) Interaction of permeant ions with channels activated by acetylcholine in Aplysia neurones. J Physiol (Lond) 297:9-45.

Mayer M, Westbrook G (1987a) The physiology of excitatory amino acids in the vertebrate central nervous system. Prog Neurobiol 28 : 197-276.

Mayer M, Westbrook G (1987b) Permeation and block of $N$-methyl$D$-aspartic acid receptor channels by divalent cations in mouse cultured central neurons. J Physiol (Lond) 394:501-527.

McManaman JL, Blosser JC, Appel SH (1981) The effect of calcium on acetylcholine receptor synthesis. J Neurosci 1:771-776.

Merlie JP, Sanes JR (1985) Concentration of acetylcholine receptor mRNA in synaptic regions of adult muscle fibers. Nature 317:66-68.

Miledi R, Parker I, Schalow G (1980) Transmitter induced calcium entry across the post-synaptic membrane at frog end-plates measured using arsenazo III. J Physiol (Lond) 300:197-212.

Nestler EJ, Greengard P eds (1984) Protein phosphorylation in the nervous system. New York: Wiley.

Parsons RL (1978) Role of calcium in desensitization at the motor end-plate of skeletal muscle. In: Calcium in drug action (Weiss GB ed), pp 289-313. New York: Plenum.

Parsons RL, Schnitzler RM, Cochrane DE (1974) Inhibition of endplate desensitization by sodium. Am J Physiol 227:96-100.

Peng HB (1984) Participation of calcium and calmodulin in the formation of acetylcholine receptor clusters. J Cell Biol 98:550-557.

Rash JE, Walrond JP, Morita M (1988) Structural and functional correlates of synaptic transmission in the vertebrate neuromuscular junction. J Electron Microsc Tech 10:153-185.

Rothman SM, Olney JW (1987) Excitotoxicity and the NMDA receptor. Trends Neurosci 10:299-301.
Rubin LL (1985) Increases in muscle $\mathrm{Ca}^{2+}$ mediate changes in acetylcholinesterase and acetylcholine receptors caused by muscle contraction. Proc Natl Acad Sci USA 82:7121-7125.

Sakmann B, Neher E eds (1983) Single-channel recording. New York: Plenum.

Salpeter MM (1987) Vertebrate neuromuscular junctions: general morphology, molecular organization and functional consequences. In: The vertebrate neuromuscular junction (Salpeter MM, ed), pp 1-54. New York: Alan R. Liss.

Sanchez JA, Dani JA, Siemen D, Hille B (1986) Slow permeation of organic cations in acetylcholine receptor channels. J Gen Physiol 87: 985-1001.

Schwartz LM, McCleskey EW, Almers W (1985) Dihydropyridine receptors in muscle are voltage-dependent but most are not functional calcium channels. Nature 314:747-751.

Silver RA, Lamb AG, Bolsover SR (1990) Calcium hotspots caused by L-channel clustering promote morphological changes in neuronal growth cones. Nature 343:751-754.

Sine SM, Steinbach JH (1984) Activation of a nicotinic acetylcholine receptor. Biophys J 45:175-185.

Sine SM, Taylor P (1979) Functional consequences of agonist-mediated state transitions in the cholinergic receptor. Studies on cultured muscle cells. J Biol Chem 254:3315-3325.

Takeda K, Gage PW, Barry PH (1982) Effects of divalent cations on toad end-plate channels. J Membr Biol 64:55-66.

Takeuchi A, Takeuchi N (1960) On the permeability of end-plate membrane during the action of transmitter. J Physiol (Lond) 154:5267.

Toyoshima C, Unwin N (1988) Ion channels of acetylcholine receptors reconstructed from images of postsynaptic membranes. Nature 336: 247-250.

Tsien RW, Lipscombe D, Madison DV, Bley KR, Fox AP (1988) Multiple types of neuronal calcium channels and their selective modulation. Trends Neurosci 11:431-438.

Zucker RS (1985) Calcium diffusion models and transmitter release in neurons. Fed Proc 44:2950-2952. 